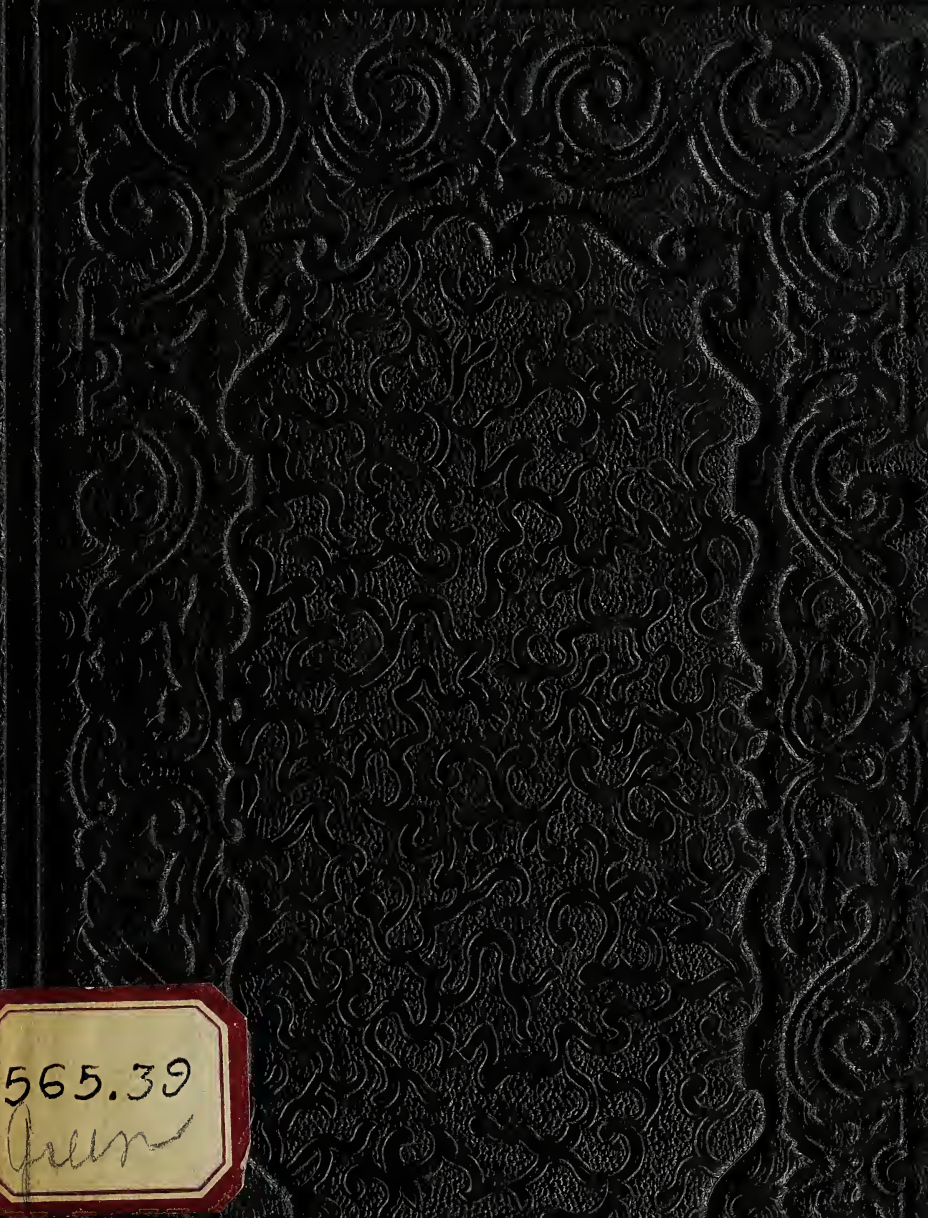




$$
\text { Ho }
$$


Pasperror of Henry

from his frena

g- Green 



THE

\section{INFERIOR SURFACE}

O F

\section{T. H E T R I L O B I T E}

DISCOVERED.

Zllustrated with Coloured ßadols.

BY JACOB GREEN, M. D.,

PROFESSOR OF CHEMISTRY IN JEFFERSON MEDICAL COLLEGE.

Multa renascentur quæ jam cecidere--HoR.

\section{PHILADELPHIA :}

PUBLISHED BY JUDAH DOBSON, 88 CHESTNUT STREET. 1839. 
EXPLANATION OF THE MODELS.

No. 1.-A large extended specimen of calymene bufo, exhibiting the upper surface of the animal.

No. 2.-The inferior surtace of the same; that of the head shows the gullar pouch, and is an exact copy from nature; that of the tail is also a copy from the original fossil, except the termination of the right horn of the crescent. The feet are imaginary.

No. 3.-The animal coiled up.

No. 4.-A transverse section this the articulations of the back.

No. 5.-A portion of the under side of I. gigas.

No. 6. $-A$ similar part of another trilobite. The entrance to the stomach was between the horns of the crescent. 
THE

\section{NFER IOR SURFACE}

OF THE

\section{TRILOBITE.}

The anatomical structure and physiological history of the whole family of the trilobites are not only involved in great obscurity, but we can scarcely hope that the most persevering efforts of the naturalist will ever be able to penetrate the darkness, or unravel the mysteries, which involve the subject. No department in the science of organic remains has been pursued of late with more zeal and curiosity than this. The trilobite furnishes the earliest example of an articulated animal found among the ancient inhabitants of our globe, and though in some few existing genera we find certain points of analogy in their or. ganization, the whole race probably became extinct after the subsidence of the great coal

\section{6}


formation. Dr. Buckland remarks, "No trilobites have yet been found in any strata more recent than the carboniferous series; and no other crustaceans, except three forms which are also entomostracous, have been noticed in strata coeval with any of those that contain the remains of trilobites; so that during the long periods that intervened between the deposition of the earliest fossilliferous strata and the termination of the coal formation, the trilobites appear to have been the chief representatives of a class which was largely multiplied into other orders and families after these earliest forms became extinct."

From the multitude of trilobites and fragments of trilobites which have been discovered in different parts of the world, most of which present nothing but portions of the upper shell of the fossil, the under side. of the animal, and the form and arrangement of the organs of locomotion, seemed an almost hopeless discovery. As the solid parts of the animal structure alone are for the most part susceptible of petrifaction, it is not to be ex- 
pected the softer portions would leave any traces whatever in the rocks which have so perfectly preserved other portions of these ancient inhabitants of our planet; for these reasons, and some others which we shall presently mention, the legs of the trilobite have been supposed to be soft and very perishable paddles.

Though much controversy formerly existed as to the true nature of the trilobite, it is now admitted by all naturalists to occupy a place among crustaceous animals. The existing genera to which they are most analogous in their general structure are the serolis, the limulus, and the branchipus. In our monograph we announced the discovery of a recent trilobite in the southern seas, near the Falkland islands: this proves to be a species of the genus serolis established by Dr. Leach. In the configuration of its upper shell it approaches exceedingly near to that of some of the trilobites; the chief difference between the recent and fossil animal consists in the crustaceous legs and antennæ of the serolis. $1^{*}$ 
The analogies existing between the limulus and our fossil, as we mentioned in another place, have been shown by Dr. Dekay and others.

In further illustration of this subject, we here add, with some slight alterations, from Dr. Buckland's admirable Bridgewater treatise, a considerable part of his section on the trilobites, which exhibits in a very condensed form the facts and opinions which have any bearing on this enquiry. I have greater satisfaction and more confidence in referring to his remarks, than in attempting to offer any thing of a similar nature drawn up by myself. After mentioning that the serolis is the nearest approach among living animals to the external form of trilobites, he adds, the next "approximation to the character of trilobites occurs in the limulus or king crab, a genus now most abundant in the seas of warm climates, chiefly in those of India, and of the coasts of America. The history of this genus is important, on account of its relation both to the existing and extinct forms of crusta. 
ceans; in it there are but slight traces of antennæ, and the shield which covers the anterior portion of the body, is expanded entirely over a series of crustaceous legs. Beneath the second, or abdominal portion of the shell, is placed a series of thin, horny, transverse plates, supporting the fibres of the branchiæ, and at the same time acting as paddles for swimming. The same disposition of laminated branchiæ is found also in the serolis. Thus while the serolis presents a union of antennæ and crustaceous legs, with soft paddles bearing the branchiæ, we have in the limulus a similar disposition of legs and paddles, and only slight traces of antennæ; in the branchipus we find antennæ, but no crustaceous legs; while the trilobite being without antennæ, and having all its legs represented by soft paddles, is by the latter condition placed near branchipus among the entomostracous crustaceans, in the order of branchiopods, whose feet are represented by ciliated paddles, combining the functions of respiration and natation.

"In the comparison here made between 
four different families of crustaceans, for the purpose of illustrating the history of the long extinct trilobites, by the analogies we find in the serolis, limulus, and branchipus; we have a beautiful example, taken from the extreme points of time of which geology takes cognizance, of that systematic and uniform arrangement of the animal kingdom, under which every family is nearly connected with adjacent and cognate families. Three of the families under consideration are among the present inhabitants of the water, while the fourth has been long extinct, and occurs only in a fossil state. When we see the most ancient trilobites thus placed in immediate contact with our living crustaceans, we cannot but recognise them as forming part and parcel of one great system of creation, connected through its whole extent by perfect unity of design, and sustained in its minutest parts by uninterrupted harmonies of organization.

"We have in the trilobites an example of that peculiar, and, as it is sometimes called, rudimentary development of the organs of 
locomotion in the class crustaceans, whereby the legs are made subservient to the double functions of paddles and lungs. The advocate for the theory of the derivation of existing more perfect species, by successive changes from more simple ancient forms, might imagine that he sees in the trilobite the extinct parent stock, from which, by a series of developments, consecutive forms of more perfect crustaceans may, during the lapse of ages, have been derived; but according to this hypothesis, we ought no longer to find the same simple condition as that of the trilobite still retained in the living branchipus, nor should the primeval form of limulus have possessed such an intermediate character, or have remained unadvanced in the scale of organization, from its first appearance in the carboniferous series, through the midway periods of the secondary formations, unto the present hour.

"Besides the above analogies between the trilobites and certain forms of living crusta. ceans, there remains a still more important 
point of resemblance in the structure of their eyes. This point deserves peculiar consideration, as it affords the most ancient, and almost the only example yet found in the fossil world, of the preservation of parts so delicate as the visual organs of animals that ceased to live many thousands, and perhaps millions of years ago. We must regard these organs with feelings of no ordinary kind, when we recollect that we have before us the identical instruments of vision, through which the light of heaven was admitted to the sensorium of some of the first created inhabitants of our planet.

"The discovery of such instruments in so perfect a state of preservation, after having been buried for incalculable ages in the early strata of the transition formation, is one of the most marvellous facts yet disclosed by geological researches; and the structure of these eyes supplies an argument of high importance in connecting together the extreme points of the animal creation. An identity of mechanical arrangements, adapted to the 
construction of an optical instrument, precisely similar to that which forms the eyes of existing insects and crustaceans, affords an example of agreement that seems utterly inexplicable without reference to the exercise of one and the same Intelligent Creative Power.

"Professor Müller and Mr. Straus have ably and amply illustrated the arrangements, by which the eyes of insects and crustaceans are adapted to produce distinct vision, through the medium of a number of minute facets, or lenses, placed at the extremity of an equal number of conical tubes, or microscopes; these amount sometimes, as in the butterfly, to the number of 35,000 facets in the two eyes, and in the dragon-fly to 14,000 .

" It appears that in eyes constructed on this principle, the image will be more distinct in proportion as the cones in a given portion of the eye are more numerous and long; that, as compound eyes see only those objects which present themselves in the axes of the individual cones, the limit of their field of 
vision is greater or smaller as the exterior of the eye is more or less hemispherical.

"If we examine the eyes of trilobites with a view to their principles of construction, we find both in their form, and in the disposition of the facets, obvious examples of optical adaptation.

"In the asaphus caudatus each eye contains at least 400 nearly spherical lenses fixed in separate compartments on the surface of the cornea. The form of the general cornea is peculiarly adapted to the uses of an animal destined to live at the bottom of the water: to look downwards was as much impossible as it was unnecessary to a creature living at the bottom; but for horizontal vision in every direction the contrivance is complete. The form of each eye is nearly that of the frustum of a cone, incomplete on that side only which is directly opposite to the corresponding side of the other eye, and in which, if facets were present, their chief range would be towards each other across the head, where no vision was required. The exterior of each eye, like 
a circular bastion, ranges nearly round three fourths of a circle, each commanding so much of the horizon, that where the distinct vision of one eye ceases, that of the other eye begins, so that in the horizontal direction the combined range of both eyes was pano. ramic.

"If we compare this disposition of the eyes with that in the three cognate crustaceans, by which we have been illustrating the general structure of the trilobites, we shall find the same mechanism pervading them all, modified by peculiar adaptations to the state and habits of each; thus in the branchipus, which moves with rapidity in all directions through the water, and requires universal vision, each eye is nearly hemispherical, and placed on a peduncle, by which it is projected to the distance requisite to effect this purpose.

"In the serolis, the disposition of the eye, and its range of vision, are similar to those in the trilobite; but the summit of the eye is less elevated; as the flat back of this animal 
presents little obstruction to the rays of light from surrounding objects.

"In the limulus, where the side eyes are sessile, and do not command the space immediately before the head, two other simple eyes are fixed in front, compensating for the want of range in the compound eyes over objects in that direction.

"In the above comparison of the eyes of trilobites, with those of the limulus, serolis, and branchipus, we have placed side by side, examples of the construction of that most delicate and complex organ the eye, selected from each extreme, and from a midway place in the progressive series of animal creations. We find in trilobites of the transition rocks, which were among the most ancient forms of animal life, the same modifications of this organ which are at the present time adapted to similar functions in the living serolis. The same kind of instrument was also employed in those middle periods of geological chronology when the secondary strata were deposited at the bottom of a warm sea, inhabited by 
limuli, in the regions of Europe which now form the elevated plains of central Germany. "The results arising from these facts are not confined to animal physiology ; they give information also regarding the condition of the ancient sea and ancient atmosphere, and the relations of both these media to light, at that remote period when the earliest marine animals were furnished with instruments of vision, in which the minute optical adaptations were the same that impart the perception of light to crustaceans now living at the bottom of the รea.

"With respect to the waters wherein the trilobites maintained their existence throughout the entire period of the transition formation, we conclude that they could not have been that imaginary turbid and compound chaotic fluid, from the precipitates of which some geologists have supposed the materials of the surface of the earth to be derived; because the structure of the eyes of these animals is such, that any kind of fluid in which shey could bave been efficient at the bottom, 
must have been pure and transparent enough to allow the passage of light to organs of vision, the nature of which is so fully disclosed by the state of perfection in which they are preserved.

"With regard to the atmosphere also we infer, that had it differed materially from its actual condition, it might have so far affected the rays of light, that a corresponding difference from the eyes of existing crustaceans would have been found in the organs on which the impressions of such rays were then received.

" Regarding light itself, also, we learn from the resemblance of these most ancient organisations to existing eyes, that the mutual relations of light to the eye, and of the eye to light, were the same at the time when crustaceans endowed with the faculty of vision were first placed at the bottom of the primeval seas, as at the present moment.

"Thus we find among the earliest organic remains, an optical instrument of most curious construction, adapted to produce vision of a peculiar kind, in the then existing representa- 
vives of one great class in the articulated division of the animal kingdom. We do not find this instrument passing onwards, as it were, through a series of experimental changes, from more simple into more complex forms; it was created at the very first, in the fulness of perfect adaptation to the uses and condition of the class of creatures, to which this kind of eye has ever been, and is still appropriate.

"If we should discover a microscope, or telescope, in the hand of an Egyptian mummy, or beneath the ruins of Herculaneum, it would be impossible to deny that a knowledge of the principles of optics existed in the mind by which such an instrument had been contrived. The same inference follows, but with cumulative force, when we see nearly four hundred microscopic lenses set side by side, in the compound eye of a fossil trilobite; and the weight of the argument is multiplied a thousand fold, when we look to the infinite variety of adaptations by which similar in. struments have been modified, through endless genera and species, from the long-lost $2^{*}$ 
trilobites, of the transition strata, through the extinct crustaceans of the secondary and tertiary formations, and thence onward throughout existing crustaceans, and the countless hosts of living insects.

"It appears impossible to resist the conclusions as to unity of design in a common Author, which are thus attested by such cumulative evidences of Creative Intelligence and Power; both, as infinitely surpassing the most exalted faculties of the human mind, as the mechanisms of the natural world, when magnified by the highest microscopes, are found to transcend the most perfect productions of human art."

We now proceed to the more immediate object of this communication, which is to describe a portion of the under side of the fossil animal, which we have named in our monograph calymene bufo.

Some time since, my attention was directed by Dr. J. J. Cohen, of Baltimore, to a number of fragments of the head of this species, obtained from the vicinity of Berkley, Va., 
and which are still preserved in his cabinet. Three or four of these fragments seemed to disclose the configuration of the whole lower surface of the buckler, in a more or less perfect state. Within a few months, another friend brought for my examination a fine large head of the same species, from the same locality, and which exhibited the under side or thorax in quite a perfect state of preserva. tion. All the fragments have precisely the same structure, so that there can be no doubt, we have now the external configuration of the entire head or buckler of the calymene bufo.

The anterior edge of the buckler of this species, as has been often observed, is marked by a deep groove or furrow, produced apparently by the junction of the upper and the under shell at this place, and which at first sight looks like the mouth of the animal; indeed, Professor Brongniart calls the elevated ridges on each side of this groove the lips. The mouth was, however, placed no doubt much farther beneath. These lips, perhaps, indicate the separation of the shell, through 
which the trilobite crept out, and left his cast off covering in the same manner as recent crustaceans leave their exuviæ. We know that the limulus polyphemus creeps through a somewhat similar opening, made along the whole anterior edge of his buckler.* In all our fragments, which exhibit the under surface of the buckler, the lower lip is reflected beneath, so as to form a kind of scroll or rolled edge, extending from one side or angle of the head to the other. Beneath this, and passing backwards towards the tail, the surface of the shell is not flat and horizontal as in the isotelus and limulus; but it swells up on each side, below the oculiferous promenences, into a kind of oval pouch, diminishing in breadth as it recedes, and at last terminates in a rounded point, below the second articula. tion of the vertebral column. 'This is the position of the gullar pouch or plate, when the animal assumed a creeping or swimming attitude; but when rolled up in the form of a ball,

* See Dr. Dekay. Annals of Natural History, vol. i. 
for the purpose of defence, then the gullar plate being composed of a single piece, and therefore not contractile, reached below the fourth articulation of the back. Some of our specimens illustrate this conformation in a very satisfactory manner. None of our fragments exhibit fairly the small surface on each side of the gullar plate, and the edge of the buckler beneath the eyes. This space was probably slightly concave, and occupied with the mandibles and their palpi, as in the genus serolis-the mouth being no doubt placed near the rounded termination of the gullar pouch.

Thus we have at last discovered nearly the whole inferior surface of the buckler of the genus calymene, a portion which includes about one third of the animal. Not the slighest impression or other vestige of antennæ can be perceived, and we may therefore pretty confidently conclude, that this genus of trilobites was destitute of those organs. Professor Demarest, in his history of fossil crustacea, seems to have ascertained by his 
useful and ingenious researches, that the irregularities of the external shells in the living species of crustaceans have a constant relation to distinct compartments in their internal organisation, and by the application of these distinctions to fossil species, he has been enabled to draw some highly curious, novel, and important conclusions respecting their internal and general structure. From my limited knowledge of the anatomy and the habits of our living crabs, I would merely suggest, that the peculiar organ in the animal economy of the trilobite, which the gullar plate above described was intended to model and protect, was perhaps the stomach, and that the spaces on each side of it covered the anterior portions of the liver.

The upper shell of the genus calymene, like that of the isotelus and dipleura, naturally and obviously divides itself into three parts, the buckler or shield-the abdomen and the caudal end. This last portion in the calymene is not covered with a thick epidermis, as in the two genera above mentioned, the articu. 
lations being all visible and somewhat difficult, in some species, to distinguish from those of the abdomen. These articulations, which are generally ten in number, are composed of a variety of immovable plates as in the other genera. The inferior surface of the caudal end of the trilobite had never been observed by any naturalist, till my friend Dr. Cohen obtained some fragments of the genus calymene from the neighbourhood of Berkley Springs, in Virginia, in some of which that structure was developed. These were kindly sent to me for examination, along with those of the buckler just described.

From our researches we have ascertained, that the inflexible margin which surrounds the caudal end or tail of the calymene bufo, is not reflected beneath the body of the animal, as might be expected, but that there is joined to it by a suture a slightly concave horizontal surface. This surface is lunate, being broader below the articulations of the vertebral column, and gradually diminishing on each side towards the horns of the crescent, which 
terminate just below the last articulations of the abdomen. This lunate surface is composed of a single thick crustaceous plate or piece. Beyond this crescent shaped piece, directly below the vertebral column, there is 2 deep cavity in the under shell of the animal, which corresponds in figure and dimensions with the gullar pouch or under surface of the buckler. By this peculiar mechanism, whenever the animal rolled itself into a ball to give protection to the soft parts of the abdomen, the protuberance under the shield would be introduced into the cavity below the tail, and thus retain the whole shell in a fixed position. In this position, with the tail closed upon the buckler, the calymene is often found.

Professor Wahlenberg considers those trilobites only as perfect animals, which are found rolled-the others being merely exuded or cast off shells, and in such alone, he remarks, can we expect to discover the organisation of the inferior surface. Most of the fragments from Berkley Springs, which have occasioned my present remarks, are found 
rolled up or partially coiled animals. All trilobites, however, have not this power; in. deed, it seems to be principally confined to those only, whose extremities are rounded and nearly equal in size. The rolled position would afford to the parodoxides and to many of the asaphs, but little security against the attacks of their enemies, and we rarely if ever find them in this attitude. The remark of Professor Wahlenberg above cited, though illustrated by the specimens now under consideration, we think of far too general a na. ture.

The deep cavity beneath the tail in the fragments which we are describing, reaches forwards towards the head as far as the ninth articulation of the back; in other words, a portion of it lies beneath the three last ab. dominal divisions. It will be recollected that the gullar pouch reaches below the fourth articulation of the back, and that the whole number of divisions in the vertebral column in the genus calymene, is twelve; we have therefore discovered in these fragments al- 
most the whole of the inferior surface, except the portion which lies below the five articulations of the back commencing with the fifth from the buckler or shield; what we shall offer in regard to this portion of the animal must be merely hypothetical, or founded on certain analogies of structure which probably existed between living crustaceous animals and the fossil remains of such as inhabited the most ancient seas.

Some of our fragments, we think, exhibit a transverse section of our trilobite, showing the position and figure of the abdominal cavity which once contained a portion of the viscera of the animal. One of the sections is through and parallel with the sixth articulation of the back: by this means we have discovered that some of the viscera were placed in a cylindrical cavity running beneath the vertebral column, and that the side lobes were only a covering and protection to the soft paddles or feet placed below, as may be seen in a similar structure in the serolis. Each of the five articulations of the abdomen, 
the under side of which we have not yet discovered, was probably furnished below, on each side of the abdominal cavity, with organs, which performed the double office of feet and lungs. Now, as our fragments develope all the inferior surface except the portion beneath these five articulations of the abdomen, it is probable that our trilobite was a decapodous animal. Professor Brongniart long ago imagined, that the reason why no traces of these organs have yet been discover. ed, is that the trilobites held that place among crustaceous animals in which the antennæ disappear, and the legs become transformed into soft paddles incapable of preservation. If this supposition be true, we shall in vain look for any further discoveries below the upper shell of the trilobite. What affords, we think, increasing probability to the opinion we have just advanced, with regard to the situation of the abdominal cavity, and the organs of locomotion below the five abdominal arches above mentioned, is, that when the animal rolled itself up for protection, this portion of the body 
would still retain nearly a rectilinear position; thus no interference would occur in the ordinary functions of the animal economy when the body was contracted.

Besides the organs of locomotion and respiration beneath the abdominal arches of the genus calymene, it is probable that on each side of the deep cavity under the caudal end there was placed a series of thin transverse plates, which also performed the combined functions of breathing and swimming: a similar disposition of laminated branchiæ may be observed also in the limulus and in the serolis. Beneath this deep cavity the heart of the animal was also probably placed.

What we have said with regard to the inferior mechanism of the trilobite, applies exclusively to the genus calymene. It is probable that this structure differs essentially in all the genera of this remarkable family. Dr. Dekay has described and figured in the first volume of the Annals of the Lyceum of $\mathrm{Na}$ tural History of New York, the under side of the buckler of the isotelus, which is very pe- 
culiar in its configuration-he describes this inferior surface as being formed by the anterior part of the buckler being reflected beneath the animal so as to form a flat horizontal plane, which terminates in a kind of lunate spine, the horns of the crescent being curved towards each other. These horns are six lines in length, and their points are sharp and translucent. We have received from Dr. Warder a specimen of this singular structure, which was found, with other fragments of the isotelus, near Springfield in Ohio. Though it lies on the rock, unaccompanied by any other fragment of the animal, its exact resemblance to the figure given by Dr. Dekay leaves no doubt that it once belonged to an isotelus. Among other conjectures respecting the uses of this crescent-shaped structure, it is observed that when the animal was attacked "it may roll itself up into a ball, as indeed it is often found, and by some mechanism these pro. cesses may be inserted into the corresponding cavities in the tail, and thus retain perma. nently a rolled position, presenting nothing $3^{*}$ 
but its calcareous covering to the enemy; or they may supply the place of antennæ, for which their form and contiguity to the mouth and brain would seem to render them pecu. liarly applicable." The first conjecture above noticed was ingenious, and will no doubt be confirmed when the lower surface of the tail is discovered. The inferior organization of the calymene bufo has at any rate given great plausibility to this opinion.

We have also carefully examined another fragment representing a similar structure. The original fossil was found in Ohio, and is now in the possession of W. Wagner, Esq. of Philadelphia. The rock on which it occurs is a gray limestone full of other petrifactions. This lunate structure differs essentially from the one noticed by Dr. Dekay; the points of the crescent are rounded and do not curve towards each other; the terminations are not raised and translucent, but the whole surface is nearly flat. It, however, formed, undoubt. edly, a portion of the under surface of some trilobite, whether that of an asaphus, an iso. 
telus, or a dipleura, we are unable now to determine. In the Geol. Trans., No. 8, Vol. I. $\mathrm{pl} .27$, there is a figure by Mr. Stokes of what is said to be the under surface of the anterior portion of the shield of an asaphus platycepha. lus from Lake Huron. Dr. Buckland, whose copy of the figure we have only seen, observes concerning it, that the entrance to the sto. mach of the animal was between these lunate processes, "analogous to that in recent crabs." The A. platycephalus is synonymous with $I$. gigus of Dr. Dekay; and if Mr. Stokes's drawing and Dr. Dekay's figure be accurate representations of nature, we think they must be drawn from analogous fragments belonging to animals at least specifically distinct.

We have called the fossil remain which has occasioned the present remarks respect. ing the organization of the under surface of the trilobite, calymene bufo, a name which we proposed some years since in our little work on these interesting reliques. Other writers have applied to it the term caly. 
mene macrophthalma, first given by Professor Brongniart, not only to this fossil, but to another, which differs essentially from it. He has given in his admirable work on this subject good figures of both animals, but his specific description refers only to plate 1 , fig. 4 , A. B. He observes, "that the species is remarkable by the prolongation of the ante. rior portion of the buckler in the form of a snout, and that its middle lobe or front, is marked on its sides by three oblique plica or wrinkles, like those on the $C$. tristani." This description applies very well to some reliques found in the Dudley rock, which we have examined, but it is perfectly obvious that the calymene bufo, which has a rounded front, and is entirely destitute of plicæ or wrinkles, cannot be included in it. We therefore took the liberty in our little work of calling by the name of calymene bufo the fossil represented on his first plate at fig. 5 , and which is so common in the United States; and of restricting the $\mathrm{C}$. macrophthalma to the ani- 


\section{3}

mals represented on the same plate at fig. 4, which are specifically distinct, and if not so called, must still remain nameless.

THE END. 



\section{FOR SALE,}

B Y

\section{J S E I I I I I I A N I ,}

Instructer in Taxidermy and Modeller in Wax and Compositions.

Green's Monograph of Trilobites, with casts. Supplement to Monograph, with casts. Megalorix Laqueatus; 18 bones.

Mosasaurus Tooth.

Scaphites Cuvieri.-Morton.

Basilosaurus. 8 fine bones.

With many other models.

J. Bravo has the exclusive right of making and vending the above, and is the only person who has had access to the original fossils, for the purpose of modelling. 






/

c.

2a

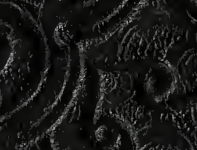

T) 640

(1)

(a) $\sqrt{3}$

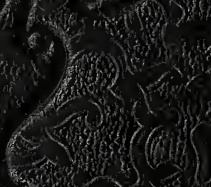

(2)

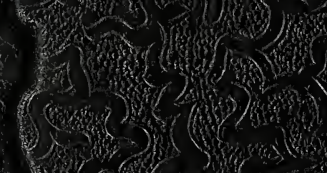

(a) $(2)$

(a)

4.

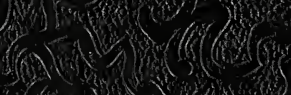

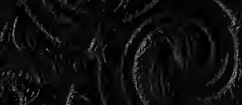

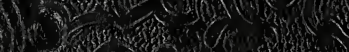

is

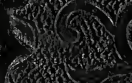

1)

(s)

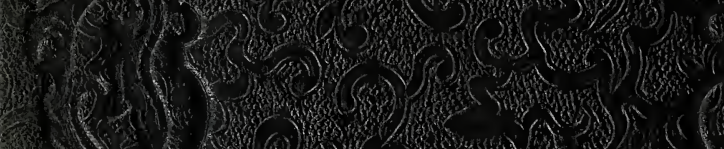

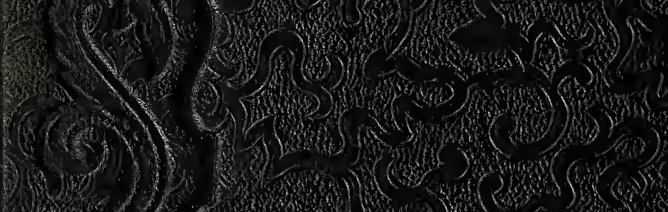

(1)

(7)

(x)

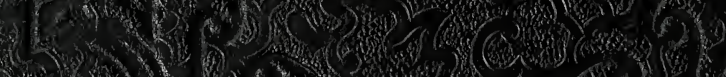

1. (3)

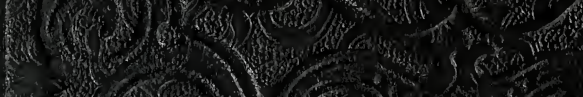

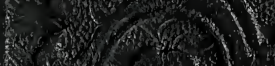

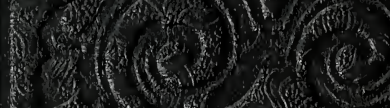

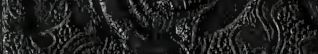

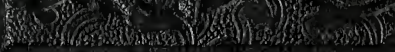

